\title{
Denaturation of glucose-6-phosphate dehydrogenase from Leuconostoc mesenteroides by guanidine hydrochloride; identification of inactive, partially unfolded, dimeric intermediates
}

\author{
J. Jeffrey Plomer and Ari Gafni \\ Institute of Geromtolugy and Department of Biological Chemistn: The Unicersity of Michigan. Ann Arbor (USA)
}

(Received 15 January 1992)

Key words: Glucose-6-phosphate dehydrogenase; Denaturation: Guanidine hydrochloride; Denaturation intermediate: Enzyme conformation

The denaturation of the dimeric enzyme glucose-6-phosphate dehydrogenase from Leuconostoc mesenteroides by guanidine hydrochloride has been studied using enzymatic activity, intrinsic fluorescence, circular dichroism, and light scattering measurements. Equilibrium experiments at $25^{\circ} \mathrm{C}$ revealed that between 0.9 and $1.2 \mathrm{M}$ denaturant the enzyme underwent a conformational change, exposing tryptophan residues to solvent, with some loss of secondary structure and a complete loss of enzymatic activity but without dimer dissociation to subunits. This inactive, partially unfolded, dimeric intermediate was susceptible to slow aggregation, perhaps due to exposure of 'sticky' hydrophobic stretches of the polypeptide chain. A second equilibrium transition, reflecting extensive unfolding and dimer dissociation, occurred only at denaturant concentrations above $1.4 \mathrm{M}$. Kinetics experiments demonstrated that in the denaturant concentration range of 1.7-1.9 $\mathrm{M}$ the fluorescence change occurred in two distinct steps. The first step involved a large, very rapid drop in fluorescence whose rate was strongly dependent on the denaturant concentration. This was followed by a small, relatively slow rise in the emission intensity, the rate of which was independent of denaturant concentration. Enzymatic activity was lost with a denaturant-concentration-dependent rate, which was approx. 3-times slower than the rate of the first step in fluorescence change. A denaturatun mechanism incorporating several unfolding intermediates and which accounts for all the above results is presented and discussed. While the fully unfolded enzyme regained up to $55 \%$ of its original activity upon dilution of denaturant to a concentration that would be expected to support native enzyme, denaturation intermediates were able to reactivate only minimally and in fact were found to aggregate and precipitate out of solution.

\section{Introduction}

In spite of extensive research over the last two decades, the way in which a protein's sequence of amino acids codes for its three-dimensional structure is not well understood [1-4]. For example, does the amino-acid sequence code for the final (native) threedimensional structure or for the correct folding of an intermediate species which, in turn, guides the folding process in the right direction [5]? This so called "pro-

Correspondence to: A. Gafni, Institute of Gerontology and Department of Biological Chemistry, The Universily of Michigan, Ann Arbor, MI 48109, USA.

Abbreviations: G6PD, glucose-6-phosphate dehydrogenase; GdnHCl, guanidine hydrochloride; $C D$, circular dichroism; $X a a$, any amino acid. tein folding problem" is particularly challenging when the protein is oligomeric. Not only must the individual polypeptide chains fold properly, but the subunits must associate correctly since their specific associations are usually vital to catalytic activity. Failure of many oligomeric enzymes to regain activity when refolded from denatured subunits has been well documented [6]. The correct folding and assembly of oligomeric proteins is, therefore, currently a problem of great importance.

Glucose-6-phosphate dehydrogenase (G6PD) from Leuconostoc mesenteroides is a dimeric protein which catalyzes the oxidation of glucose 6-phosphate to 6phosphoglucono- $\delta$-lactone by either $\mathrm{NADP}^{+}$or $\mathrm{NAD}^{+}$ [7]. The dimeric molecular weight is 103700 [8]. Interestingly, $\mathrm{NAD}^{+}$binds to the enzyme more weakly than $\mathrm{NADP}^{+}$, but causes a larger conformational change than the latter coenzyme $[9,10]$. Although this protein has been crystallized, the detailed three-dimensional 
structure has not been reported yet [11]. Several studies have shown that the association of the two identical subunits of $L$. mesenteroides G6PD is vital for enzymatic activity [12,13]. Haghighi and Levy [12] measured the kinetics of renaturation of G6PD from urea-denatured subunits, and proposed a model in which the unfolded subunits rapidly refold to an inactive structure that can dimerize slowly to generate native enzyme. Renatured and native enzymes were indistinguishable based on physicochemical and enzymological criteria.

The purpose of the present study was to explore the denaturation of G6PD under equilibrium conditions using increasing concentrations of the denaturant $\mathrm{GdnHCl}$ in an effort to determine the relationship between enzymatic activity, folding and assnciation of G6PD subunits. Several experimental properties which reflect different aspects of the enzyme's structural integrity were monitored throughout the course of the equilibrium denaturation. Thus, enzymatic activity was monitored to determine when active site integrity is lost, while intrinsic protein fluorescence was utilized to detect changes in the local environment of tryptophan residues, as exposure of such residues to solvent is known to affect their fluorescence. Circular dichroism (CD) was used to monitor changes in the secondary structure of the G6PD molecule, while light scattering was utilized to follow the enzyme's dissociation pattern. Denaturation curves were obtained for each of these properties that represent equilibrium structural rearrangements of G6PD. Also, the rate of reaching equilibrium was determined by measuring the kinetics of inactivation, unfolding and dissociation. The resulis demonstrate that complete inactivation as well as a substantial amount of unfolding occur at $\mathrm{GdnHCl}$ concentrations well below those needed to induce the dissociation of the enzyme into monomeric subunits. Unlike many oligomeric enzymes, inactivation of G6PD thus distinctly precedes its dissociation to subunits. The inactive, partially unfolded, dimeric intermediates which form are highly susceptible to aggregation and reactivate only minimally upon dilution of $\mathrm{GdnHCl}$. In fact, dilution of the denaturant enhanced aggregation and precipitation of the enzyme possibly indicating that in the partially unfolded dimers some hydrophobic stretches are exposed which have the tendency to adhere to one another.

\section{Materials and Methods}

G6PD in lyophilized form as well as glucose-6-phosphate and NADP ${ }^{+}$were purchased from Sigma. Ultrapure $\mathrm{GdnHCl}$ was purchased from Calbiochem. Reagents for the Bradford protein assay [14] were purchased from Bio-Rad. All other chemicals were of reagent grade.
Stock solutions of G6PD were made by reconstituting the lyophilized enzyme with $50 \mathrm{mM}$ Tris- $\mathrm{HCl}(\mathrm{pH}$ 7.8). Enzyme homogeneity was verified by SDS-PAGE to be better than $99 \%$. Stock solutions of G6PD to be used in light scattering experiments (see below) were passed through a Sephadex G-200 column to remove a small amount (3\%) of high-molecular-weight protein, likely aggregated G6PD. Concentration of G6PD was determined from the absorbance at $280 \mathrm{~nm}$ using the extinction coefficient $E_{0.1 \% .280}=1.15 \mathrm{~cm}^{-1}$ [8]. Alternatively, protein concentration was determined by the method of Bradford [14]. The ratio of the absorbance of G6PD at $280 \mathrm{~nm}$ to that at $260 \mathrm{~nm}$ was found to be 1.95 , indicating that G6PD was in the apo form [8]. Also, glucose 6-phosphate was added to a sample of the enzyme, and no change in absorbance at $340 \mathrm{~nm}$ was detected, confirming that G6PD was in the apo form. The activity of the enzyme was determined spectrophotometrically by measuring the rate of NADPH production (absorbance at $340 \mathrm{~nm}$ ) as described by Olive et al. [15], using a Milton-Roy Spectronic 1201 spectrophotometer, with one unit of activity being defined as the production of $1.0 \mu \mathrm{mol}$ NADPH per min (initial velocity). The reaction mixture consisted of 2.50 $\mathrm{mM}$ glucose 6-phosphate and $0.1 \mathrm{mM} \mathrm{NADP}^{+}$in 50 $\mathrm{mM}$ Tris- $\mathrm{HCl}(\mathrm{pH} 7.8)$, maintained at $25^{\circ} \mathrm{C}$. Manageable NADPH production rates were obtained using G6PD concentrations in the range of $0.05-0.20 \mu \mathrm{g} / \mathrm{ml}$. The specific activity of G6PD was $238 \pm 16$ units/mg using the above reaction conditions. Stock solutions of $\mathrm{GdnHCl}$ were made in $50 \mathrm{mM}$ Tris- $\mathrm{HCl}(\mathrm{pH} \mathrm{7.8)}$, and the concentration of denaturant determined from the refractive index as described by Nozaki [16].

Denaturation of G6PD was performed in the following manner. Stock solutions of G6PD (typically 5 $\mathrm{mg} / \mathrm{ml})$ and $\mathrm{GdnHCl}(8 \mathrm{M})$ were mixed with $50 \mathrm{mM}$ Tris- $\mathrm{HCl}$ (pH 7.8) with G6PD being added last, to give the desired concentration of protein and denaturant (see Figs. for details). Each mixture was allowed to equilibrate by incubation at $25^{\circ} \mathrm{C}$ for $24 \mathrm{~h}$, a sufficient time to reach the limiting values of all enzyme properties listed below at each $\mathrm{GdnHCl}$ concentration used, before either enzymatic activity, protein fluorescence, or $\mathrm{CD}$ was measured as described in more detail below. Enzymatic activity was measured in the presence of very low concentration of $\mathrm{GdnHCl}$ (typically $<3 \mathrm{mM}$ ). While it is possible that an undetected, instantaneous, partial reactivation could have occurred upon addition of the enzyme to the assay mixture, no reactivation of the enzyme was observed during the assay as evidenced by a completely linear NADPH production curve. Light scattering (described in more detail below) was used in order to identify the $\mathrm{GdnHCl}$ concentration needed to dissociate G6PD to subunits. Protein-GdnHCl mixtures on which light scattering measurements were done were incubated at $25^{\circ} \mathrm{C}$ for 
only $2 \mathrm{~h}$ in order to minimize the amount of G6PD aggregation, a slow process which by $24 \mathrm{~h}$ at certain $\mathrm{GdnHCl}$ concentrations results in a large increase in light scattering intensity, which would obscure the expected $50 \%$ decrease in light scattering when the dimeric G6PD dissociates. A $2 \mathrm{~h}$ incubation time was chosen since, in the presence of $1.4 \mathrm{M} \mathrm{GdnHCl}$, it is sufficient to completely inactivate G6PD, an event whose possible relation to dissociation of enzyme subunits was tested. The kinetics of G6PD denaturation were determined by measuring either enzymatic activity, protein fluorescence, or light scattering at various times after mixing (see Fig. 2-4 and 6 for details).

Renaturation of G6PD was performed in the following manner. Firstly, the enzyme was denatured by mixing stock solutions of G6PD and $\mathrm{GdnHCl}$ with 50 $\mathrm{mM}$ Tris- $\mathrm{HCl}$ ( $\mathrm{pH} 7.8$ ), with G6PD being added last, to give the desired molar concentration of $\mathrm{GdnHCl}$ ([GdnHCl]) (see Fig. 5) and $X \mu \mathrm{g} / \mathrm{ml}$ protein, where $\mathrm{X}=([\mathrm{GdnHCl}])(\mathrm{i} 25) /(0.35)$. Each mixture was allowed to incubate at $25^{\circ} \mathrm{C}$ for $2 \mathrm{~h}$. Secondly, renaturation was facilitated by rapidly diluting each solution into $50 \mathrm{mM}$ Tris- $\mathrm{HCl}(\mathrm{pH} \mathrm{7.8)}$ to give the low residual $\mathrm{GdnHCl}$ concentration of $0.35 \mathrm{M}$ and $125 \mu \mathrm{g} / \mathrm{ml} \mathrm{G6PD}$ and allowing the sample to equilibrate by incubation at $25^{\circ} \mathrm{C}$ for $24 \mathrm{~h}$. Subsequently, each solution was filtered through a Gelman Sciences $0.2 \mu \mathrm{m}$ disposable syringe filter and enzymatic activity, protein concentration in solution, and light scattering were measured. Values were expressed relative to a control in which the enzyme was not denatured in $\mathrm{GdnHCl}$ but was incubated under identical renaturation conditions.

G6PD which precipitated during renaturation (following denaturation with $1.4 \mathrm{M} \mathrm{GdnHCl}$ ) was isolated by centrifugation and mixed with $4.0 \mathrm{M} \mathrm{GdnHCl,} 50$ $\mathrm{mM}$ Tris- $\mathrm{HCl}(\mathrm{pH} \mathrm{7.8)}$ in order to redissolve the enzyme. To facilitate reactivation of this redissolved enzyme, it was subsequently diluted into a solution of $\mathbf{5 0}$ $\mathrm{mM}$ Tris- $\mathrm{HCl}(\mathrm{pH} 7.8)$ to give a low residual $\mathrm{GdnHCl}$ concentration of $0.35 \mathrm{M}$ and $125 \mu \mathrm{g} / \mathrm{ml}$ protein. This mixture was incubated at $25^{\circ} \mathrm{C}$ for $24 \mathrm{~h}$, filtered through a Gelman Sciences $0.2 \mu \mathrm{m}$ disposable syringe filter, and assayed for enzymatic activity and protein concentration in solution, with values expressed relative to a control in which the enzyme was not denatured in $\mathrm{GdnHCl}$ but was incubated under identical renaturation conditions.

Intrinsic protein fluorescence measurements were performed with a Spex Fluorolog II fluorometer with $0.25-\mathrm{m}$ single grating excitation monochromator and a $0.25-\mathrm{m}$ double grating emission monochromator. The change in G6PD fluorescence intensity was monitored at $340 \mathrm{~nm}$ with the excitation wavelength set of $290 \mathrm{~nm}$. The bandwidth for excitation was $1.8 \mathrm{~nm}$, while that for emission was $7.2 \mathrm{~nm}$, unless otherwise noted. Back- ground fluorescence due to buffer and $\mathrm{GdnHCl}$ solutions was negligible when these conditions were used. All measurements were made at $25^{\circ} \mathrm{C}$.

Light scattering measurements were performed at $25^{\circ} \mathrm{C}$ using the Fluorolog II system described above. Scattered light intensity was measured at $90^{\circ}$ to the incident beam using a wavelength of $450 \mathrm{~nm}$ and with the incident as well as the scattered light vertically polarized. The bandwidths were $1.8 \mathrm{~nm}$ for the incident beam and $14.4 \mathrm{~nm}$ for the scattered beam. In the denaturation experiments, the concentration of G6PD was $500 \mu \mathrm{g} / \mathrm{ml}$ in a $0.4 \times 1.0 \mathrm{~cm}$ quartz cuvette. In order to remove dust particles before measurement, solutions were passed through a $0.2 \mu \mathrm{m}$ Gelman Sciences syringe filter directly into the quartz cuvette for immediate measurement. The ratio of apparent molecular weights in the presence, $M_{\mathrm{i}}$, and the absence, $M_{0}$, of $\mathrm{GdnHCl}$ was determined using the following equation $[17,18]$ :

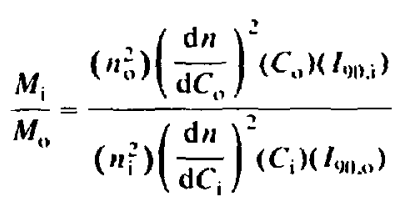

where $n$ represents the refractive index of the medium, $\mathrm{d} n / \mathrm{d} C$ is the refractive index increment due to the increase of protein concentration $(C)$ at constant chemical potential, and $I$ is the scattered light intensity at $90^{\circ}$ after subtraction of the scattering of the solvent. Subscripts $i$ and $o$ indicate the system with and without $\mathrm{GdnHCl}$, respectively. The refractive index increment was assumed to decrease linearly from 0.177 to 0.130 over the $\mathrm{GdnHCl}$ concentration range of 0 to $5.7 \mathrm{M}$ as described by Liang et al. [17]. The refractive index of the medium for the same range of $\mathrm{GdnHCl}$ concentrations was measured with an Abbé type refractometer.

The validity of using light scattering to detect changes in protein molecular weight was tested empirically by measuring light scattering intensity as a function of protein concentration $(10-500 \mu \mathrm{g} / \mathrm{ml})$ for native G6PD as well as for the native form of several standard proteins of known molecular weight (30-150 $\mathrm{kDa}$ ). In each case it was found that light scattering intensity increased linearly with protein concentration, and the slope of this increase was proportional to the molecular weight of the protein being measured in all cases. Therefore, it is clear that at any given protein concentration the light scattering intensity is proportional to the protein's molecular weight.

$\mathrm{CD}$ measurements were made at $25^{\circ} \mathrm{C}$ using a Jasco J-40 Recording Spectropolarimeter equipped with a $\mathrm{CD}$ attachment. The change in $\mathrm{CD}$ signal was monitored at $220 \mathrm{~nm}$. The concentration of G6PD was 500 $\mu \mathrm{g} / \mathrm{ml}$ in $0.1 \mathrm{~cm}$ path-length quartz cuvette. 


\section{Results}

\section{Denaturation of G6PD}

Fig. 1 shows the dependence of enzymatic activity, intrinsic fluorescence, and $\mathrm{CD}$ on the concentration of $\mathrm{GdnHCl}$ under equilibrium conditions. Enzymatic activity was lost in a single, sharp, transition centered at 1.1 M GdnHCl, and the enzyme was completely inactivated by $1.2 \mathrm{M} \mathrm{GdnHCl}$. The position of this transition was found not to depend on the concentration of G6PD in the range of $500-0.5 \mu \mathrm{g} / \mathrm{ml}$ (data not shown). The intrinsic fluorescence of G6PD at $340 \mathrm{~nm}$ was reduced with increasing concentrations of $\mathrm{GdnHCl}$, to a limiting value (reached above $3.0 \mathrm{M}$ denaturant) of $58 \%$ of the fluorescence without denaturant. However, in contrast to the inactivation, the fluorescence decline occurred in two, well resolved, steps of approximately the same size. The first, sharp, step coincided with the loss of enzymatic activity, since it was cuntered at 1.10 $\mathrm{M} \mathrm{GdnHCl}$. The second phase was less steep and was complete by $3.0 \mathrm{M} \mathrm{GdnHCl}$. The reduction in fluorescence intensity was due in part to a shift in the emission wavelength maximum from $340 \mathrm{~nm}$ in the absence of $\mathrm{GdnHCl}$ to $363 \mathrm{~nm}$ at $\mathrm{GdnHCl}$ concentrations greater than $3.0 \mathrm{M}$. Moreover, this shift occurred in a two-step manner paralleling the decrease in intensity. The change in $C D$ at $220 \mathrm{~nm}$, a measure of protein secondary structure, with $\mathrm{GdnHCl}$ concentration also showed a two step transition similar to that displayed by the fluorescence. These results show that G6PD undergoes a conformational change, exposing tryptophan residues to solvent, with some loss of secondary

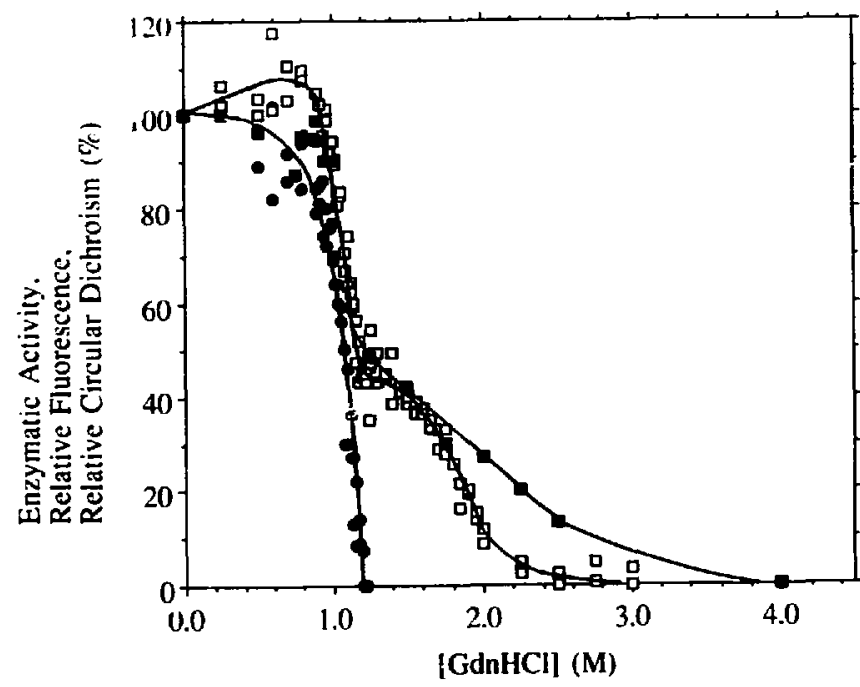

Fig. 1. Denaturation of $50 \mu \mathrm{g} / \mathrm{ml}$ G6PD by $\mathrm{GdnHCl}$, at the concentration of denaturant indicated. Each mixture was allowed to equilibrate by incubation at $25^{\circ} \mathrm{C}$ for $24 \mathrm{~h}$ before the following measurements were made: enzymatic activity ( $\bullet$; relative emission intensity at $340 \mathrm{~nm}$ (excitation wavelength $=290 \mathrm{~nm}(\square)$; and relative $C D$ at $220 \mathrm{~nm}(500 \mu \mathrm{g} / \mathrm{ml} \mathrm{G6PD)}(\mathrm{E})$, with the difference between native and 4.0 $\mathrm{M} \mathrm{GdnHCl}$ denatured enzyme taken as $100 \%$.

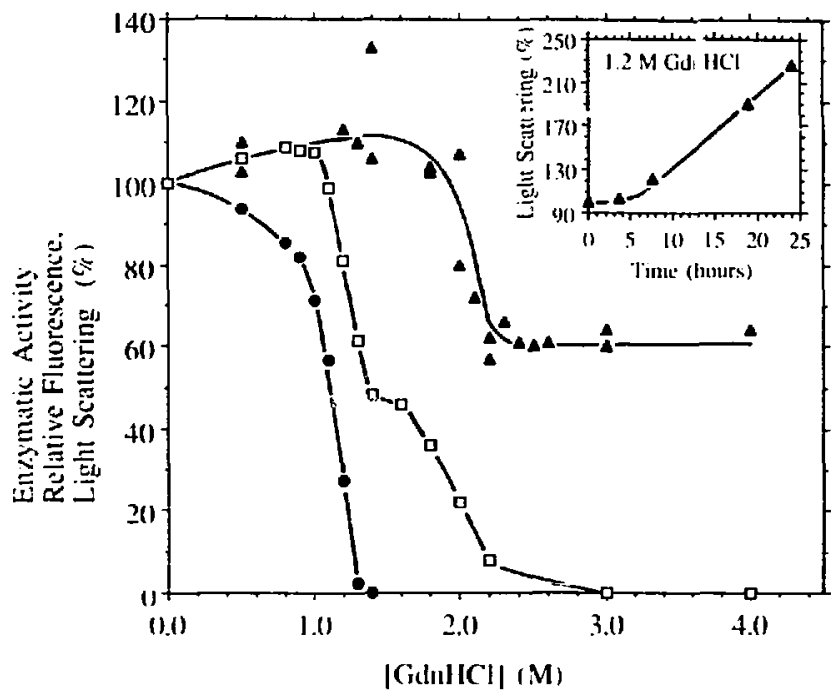

Fig. 2. Dependence of G6PD light scattering on GdnHCl concentration. $500 \mu \mathrm{g} / \mathrm{ml}$ G6PD and the concentration of denaturant indicated were allowed to incubate at $25^{\circ} \mathrm{C}$ for $2 \mathrm{~h}$ before the scattered light intensity was measured and expressed as $\left(M_{1} / M_{0}\right) \times 100 \%(\Delta)$. Enzymatic activity $(\bullet)$ and relative emission intensity at $340 \mathrm{~nm}$ (excitation wavelength $=290 \mathrm{~nm}$ ) with the difference between native and 4.0 M GdnHCl denatured enzyme taken as $100 \%$ ( $\square$ ) were also measured under the same experimental conditions as the light scattering. (Inset) Time-course of change in light scattering of enzyme in $1.2 \mathrm{M} \mathrm{GdnHCl}$.

structure and a complete loss of active site integrity between 0.9 and $1.2 \mathrm{M} \mathrm{GdnHCl}$ while a second transition, reflecting more extensive unfolding of the enzyme, begins only at $\mathrm{GdnHCl}$ concentrations above 1.4 $M$. The denaturation transitions of $50 \mu \mathrm{g} / \mathrm{ml} \mathrm{G6PD,}$ incubated at $25^{\circ} \mathrm{C}$ for $24 \mathrm{~h}$, as monitored through enzymatic activity and fluorescence in the presence of a saturating concentration of either glucose-6-phosphate or NADP ${ }^{+}$were also measured (data not shown). The concentrations used were ten fold the dissociation constants for each of these ligands [9], and the denaturation transitions were unaffected by the presence of these ligands.

Insight into the molecular events involved in the two transitions described above was provided by the results of the light scattering experiments, presented in Fig. 2, which showed no decrease in G6PD molecular weight throughout the $\mathrm{GdnHCl}$ concentration range of $0-1.9$ $M$, indicating that no dissociation of G6PD to subunits occurs. In fact, the light scattering intensity of samples incubated with $1.0-1.4 \mathrm{M} \mathrm{GdnHCl}$ began to increase slowly after about $4 \mathrm{~h}$, indicating the gradual formation of high molecular weight aggregates. This aggregation. depicted in Fig. 2 (inset), occurred without a loss of protein from solution as precipitate. To avoid interference of this slow aggregation in the light scattering experiments all the data presented in Fig. 2 were recorded following a $2 \mathrm{~h}$ incubation of the enzyme in $\mathrm{GdnHCl}$. While complete equilibration was possibly 
not reached during this shortened incubation time, it is important to note that at $1.4 \mathrm{M} \mathrm{GdnHCl} \mathrm{G6PD} \mathrm{was}$ completely inactive but no dissociation of the enzyme to subunits occurred. A dissociation of the G6PD dimer to monomeric subunits only occurred at concentrations of $\mathrm{GdnHCl}$ where the second transition in fluorescence and $C D$ take place. This was indicated by the decrease in light scattering intensity by about a half in the range of 2.0-2.2 M GdnHCl. The kinetics of this decrease was too fast $(<20 \mathrm{~s})$ to be measured with our methods (data not shown). This observation demonstrates that an inactive, partially unfolded, dimeric species of G6PD forms during denaturation between 0.9 and $1.2 \mathrm{M}$ $\mathrm{GdnHCl}$ at $25^{\circ} \mathrm{C}$. This denaturation intermediate is susceptible to slow aggregation. Unfolding of G6PD subunits appears to be complete at $\mathrm{GdnHCl}$ concentration between $3.0-4.0 \mathrm{M}$, as indicated by the lack of further substantial changes in any of the spectroscopic parameters followed.

The kinetics of G6PD denaturation upon mixing of the enzyme with $1.4 \mathrm{M} \mathrm{GdnHCl}$ as described in Materials and Methods were followed through both the loss of enzymatic activity and the reduction in tryptophan fluorescence as shown in Fig. 3. Both followed firstorder kinetics with rate constants, evaluated from the data, of $0.052 \mathrm{~min}^{-1}$ and $0.165 \mathrm{~min}^{-1}$ for the loss of enzymatic activity and reduction in fluorescence, respectively. The approximately 3 -fold difference between these rate constants implies that the two parameters reflect different events in G6PD unfolding with fluorescence being lost in a parallel transition which does not affect the enzymatic activity of G6PD. Enzymatic activity at the earliest recorded time (time zero in Fig. 3 but approx. $60 \mathrm{~s}$ following mixing) was $87 \%$ of

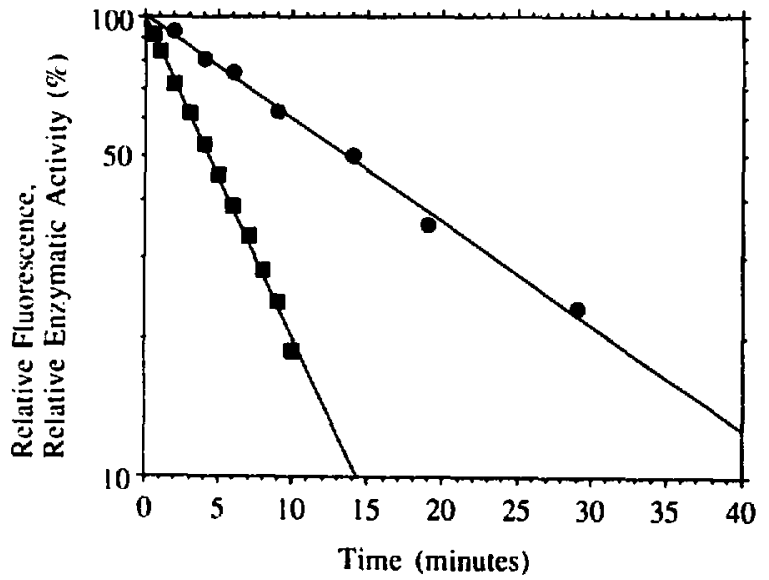

Fig. 3. Kinetics of G6PD $(250 \mu \mathrm{g} / \mathrm{ml})$ denaturation in $1.4 \mathrm{M} \mathrm{GdnHCl}$ at $25^{\circ} \mathrm{C}$ as monitored by enzymatic activity $(\bullet)$ and protein fluorescence $(\square)$. The initial activity and fluorescence measurements (time zeros) were made at approx. 60 and $20 \mathrm{~s}$ after mixing, respectively. For fluorescence measurements, the difference between the initial measurement and the measurement taken after 25 min was taken as $100 \%$

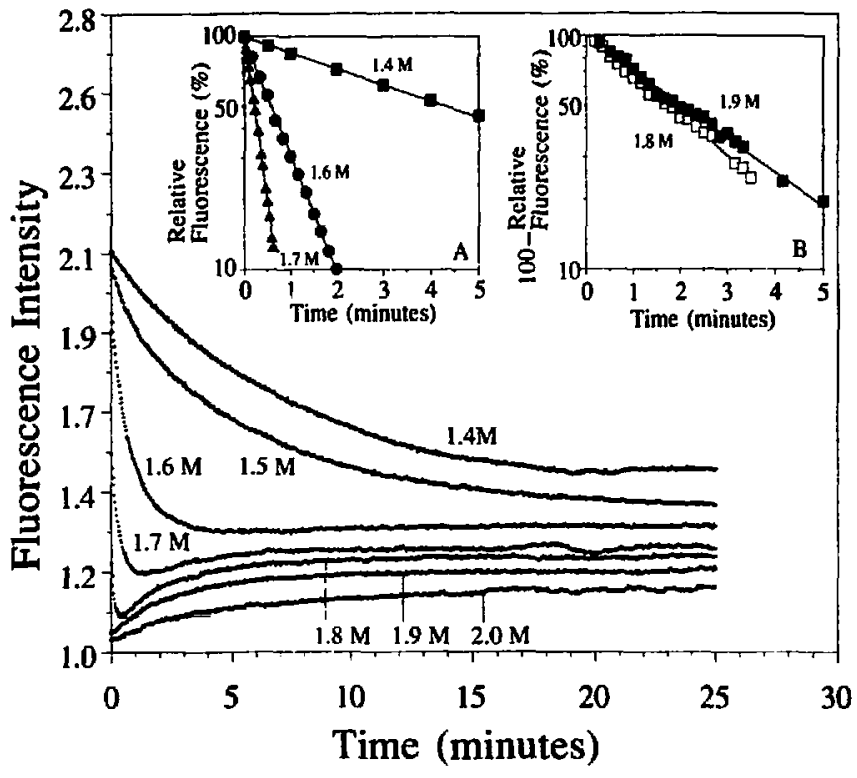

Fig. 4. Time-course of denaturation of G6PD $(250 \mu \mathrm{g} / \mathrm{ml})$ in the various concentrations of $\mathrm{GdnHCl}$ indicated as monitored by protein fluorescence at $340 \mathrm{~nm}$ (excitation wavelength $290 \mathrm{~nm}$ ). The initial measurement (time zero) was made approx. $20 \mathrm{~s}$ after mixing. Inset A; Semi-log plot of the initial drop in fluorescence observed in $1.4 \mathrm{M}$ (a), $1.6 \mathrm{M}(\bullet)$, and $1.7 \mathrm{M}(\Delta)$ mixtures, with the difference between the initial fluorescence intensity and the intensity at its minimum taken as $100 \%$. Inset B; Semi-log plot of the increase in fluorescence which follows the initial drop, as observed in the $1.8 \mathrm{M} \mathrm{GdnHCl}$ mixture ( $\square$ ), and in the $1.9 \mathrm{M} \mathrm{GdnHCl}$ mixture ( $(\mathrm{)})$. The difference in intensity between the minimum value of fluorescence and that observed after $25 \mathrm{~min}$ were taken as $100 \%$.

that of native enzyme. This rapid initial slight loss of enzymatic activity might be due to the high ionic strength imparted by $\mathrm{GdnHCl}$ to the mixture, which could have an immediate, but small, inhibitory effect on G6PD's activity independent of unfolding.

That the unfolding of G6PD involves distinct kinetic intermediates is demonstrated by the data in Fig. 4, which describes the change in fluorescence intensity with time upon mixing the enzyme with various concentrations of $\mathrm{GdnHCl}$. At all concentrations of the denaturant, an initial first-order decline in fluorescence was observed, whose rate rapidly increased with increasing $\mathrm{GdnHCl}$ concentrations. The first-order rate constants for this initial decline in fluorescence were $0.165 \mathrm{~min}^{-1}, 1.14 \mathrm{~min}^{-1}$, and $3.29 \mathrm{~min}^{-1}$ when G6PD was mixed with $1.4,1.6$ and $1.7 \mathrm{M} \mathrm{GdnHCl}$, respectively (Fig. 4, inset A). At Gdn $\mathrm{HCl}$ concentrations of $1.7 \mathrm{M}$ and above, the kinetics of fluorescence change became biphasic. For example, mixing G6PD with 1.8 $\mathrm{M} \mathrm{GdnHCl}$ resulted in a rapid initial drop in fluorescence $(<30 \mathrm{~s})$ followed by a relatively slow first-order recovery (Fig. 4 , inset $B$ ) to the final levels observed in equilibrium measurements. The rate constant for this recovery was $0.37 \mathrm{~min}^{-1}$. It is important to note that the rapid initial drop in fiuorescence was accompanied by inactivation of G6PD, which lost $90 \%$ of its enzy- 


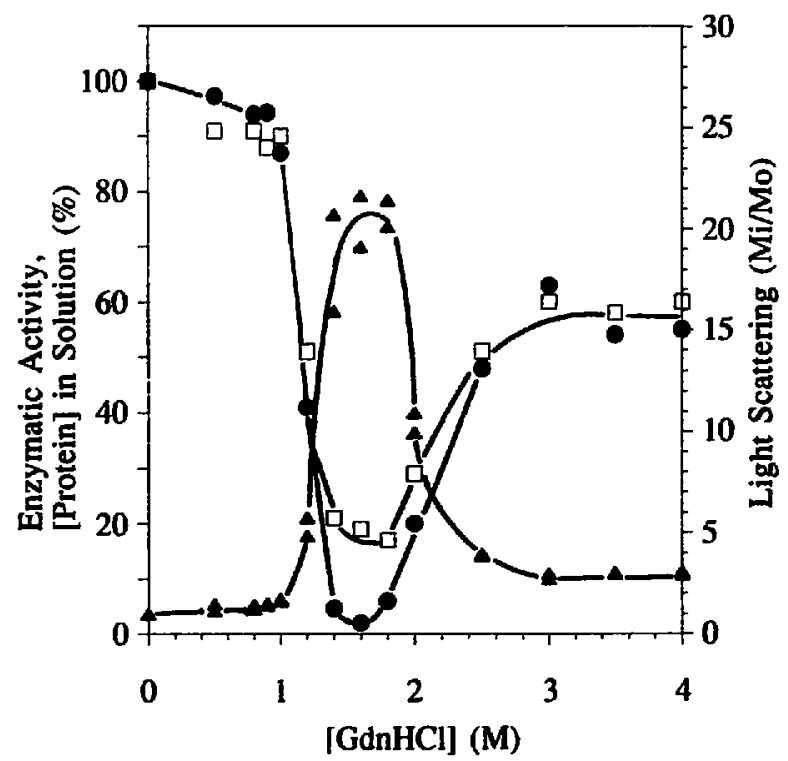

Fig. 5. Renaturation of G6PD following enzyme denaturation in the concentration of $\mathrm{GdnHCl}$ indicated ([GdnHCl]) at $25^{\circ} \mathrm{C}$ for $2 \mathrm{~h}$. The ratio of G6PD concentration to [GdnHCl] was the same in all samples such that when the renaturation was induced, by rapidly diluting each solution into the same buffer, identical GdnHCl concentration of $0.35 \mathrm{M}$ and $125 \mu \mathrm{g} / \mathrm{ml}$ G6PD were obtained. The samples were allowed to equilibrate by incubation at $25^{\circ} \mathrm{C}$ for $24 \mathrm{~h}$. Subsequently, each solution was filtered through a Gelman Sciences $0.2 \mu \mathrm{m}$ disposable syringe filter prior to making measurements. Enzymatic activity ( () ; concentration of protein remaining in solution (口); scattered light intensity expressed as $\left(M_{i} / M_{0}\right)(\triangle)$. Values were expressed relative to a control in which the enzyme was not denatured in $\mathrm{GdnHCl}$ but was incubated under identical renaturation conditions.

matic activity within $30 \mathrm{~s}$ when mixed with $1.8 \mathrm{M}$ $\mathrm{GdnHCl}$ (data not shown). In contrast to the strong dependence of the initial drop in fluorescence on the $\mathrm{GdnHCl}$ concentration, the first-order increase which followed was found to be virtually identical when 1.8 and $1.9 \mathrm{M} \mathrm{GdnHCl}$ were used (Fig. 4, inset B). The rate constant in the latter case being $0.33 \mathrm{~min}^{-1}$.

\section{Renaturation of G6PD}

The data presented in Fig. 5 show that the fraction of denatured G6PD that can be reactivated upon dilution of the denaturant critically depended on the concentration of GdnHCl used for denaturation. Practically no enzymatic activity was regained when G6PD inactivated in 1.4-1.8 M GdnHCl was diluted. Approx. $30 \%$ of the protein precipitated out of solution upon dilution of denaturant from initial values in the above range, and the diluted solutions were visibly cloudy. The G6PD remaining in solution, approx. 20\%, was practically inactive and highly aggregated as shown by the high light scattering values.

Interestingly, the percent reactivation which was obtained from dilution of G6PD denatured in $1.8 \mathrm{M}$ $\mathrm{GdnHCl}$ critically depended on the length of time the enzyme was allowed to denature at $25^{\circ} \mathrm{C}$ (Fig. 6). The percent reactivation dropped from approx. 28 to $6 \%$ as the denaturation time increased from $20 \mathrm{~s}$ to more than $9 \mathrm{~min}$. This denaturation time period corresponded to the time-frame in which the enzyme's fluorescence increased, as is shown in the superimposed fluorescence intensity time-course. It is important to note again that this fluorescence recovery was preceded by a rapid drop in fluorescence and by inactivation of G6PD.

G6PD denatured with $\mathrm{GdnHCl}$ concentrations greater than $2.0 \mathrm{M}$ allowed a higher fraction of enzymatic activity to be regained, concomitant with less precipitation (Fig. 5). Furthermore, the specific enzymatic activity (i.e., total enzymatic activity/[protein] in solution) of the fraction of G6PD which remained in solution steadily increased, approaching $100 \%$, as higher concentrations of $\mathrm{GdnHCl}$ were used in the denaturation step. Even under these conditions, however, approx. $45 \%$ of the protein precipitated from solution.

When G6PD which had precipitated during renaturation was isolated by centrifugation and mixed with $4.0 \mathrm{M} \mathrm{GdnHCl}, 50 \mathrm{mM}$ Tris- $\mathrm{HCl}(\mathrm{pH} \mathrm{7.8)}$, the protein completely dissolved. In order to facilitate reactivation,

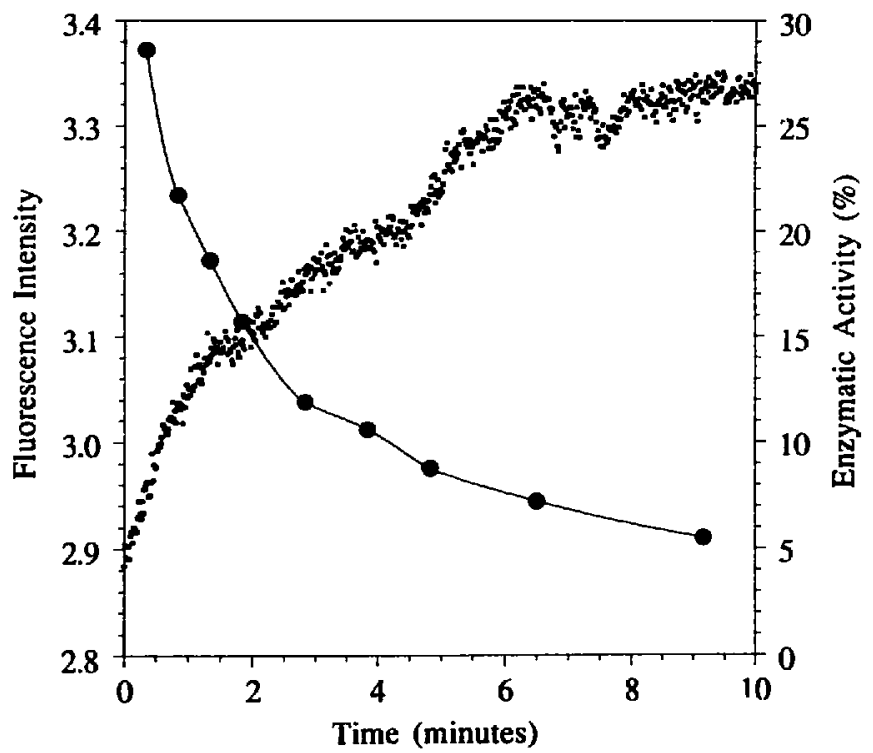

Fig. 6. Effect of denaturation time in $1.8 \mathrm{M} \mathrm{GdnHCl}$ on G6PD renaturation. Stock solutions of G6PD and $\mathrm{GdnHCl}$ were mixed to give $607 \mu \mathrm{g} / \mathrm{ml}$ protein and $1.8 \mathrm{M} \mathrm{GdnHCl}$. This mixture was incubated at $25^{\circ} \mathrm{C}$, and the fluorescence intensity at $340 \mathrm{~nm}$ (excitation wavelength $=290 \mathrm{~nm}$ ) was followed with time $(\mathbb{0})$. The initial measurement (time zero) was made approx. $20 \mathrm{~s}$ after mixing. Aliquots were removed at various times and reactivation was facilitated by diluting each aliquot into $50 \mathrm{mM}$ Tris- $\mathrm{HCl}(\mathrm{pH} 7.8)$ to give a low residual $\mathrm{GdnHCl}$ concentration of $0.37 \mathrm{M}$ and $125 \mu \mathrm{g} / \mathrm{ml}$ G6PD. Each diluted aliquot was allowed to equilibrate by incubation at $25^{\circ} \mathrm{C}$ for $18 \mathrm{~h}$ before enzymatic activity was measured ( $\bullet$ ), with values expressed relative to a control in which the enzyme was not denatured in $\mathrm{GdnHCl}$ but was incubated under identical renaturation conditions. 
this solution was subsequently diluted with $50 \mathrm{mM}$ Tris- $\mathrm{HCl}(\mathrm{pH} 7.8)$, bringing the $\mathrm{GdnHCl}$ concentration to $0.35 \mathrm{M}$ and giving a protein concentration equal to $125 \mu \mathrm{g} / \mathrm{ml}$. After $2 \mathrm{~h}$ incubation at $25^{\circ} \mathrm{C}$, this mixture was filtered through a Gelman Sciences $0.2 \mu \mathrm{m}$ syringe filter to remove reprecipitated protein, which amounted to approx. $75 \%$ of the protein. The $25 \%$ protein remaining in solution had a specific activity $60 \%$ that of fully active G6PD. That the reactivated precipitate possessed only $60 \%$ specific activity is probably due to the presence of soluble, inactive aggregates not removed by filtration. However, this experiment does demonstrate that precipitated G6PD is reactivatible.

\section{Discussion}

The dissociation of oligomeric enzymes to subunits upon exposure to appropriate concentrations of a denaturant is often the first step in denaturation and usually results in the loss of enzymatic activity [19-22]. This observation reflects the fact that the intersubunit interactions are weak relative to the interactions that stabilize the secondary and tertiary structure of each subunit. In contrast, the experimental evidence presented here strongly supports the conclusion that the first step in G6PD denaturation, in which enzymatic activity is completely lost and the intrinsic fluorescence is partially lost, occurs while the enzyme is in its dimeric form, and hence does not involve its dissociation. The simplest mechanism for the denaturation of G6PD which is compatible with this observation is:

$\mathrm{D} \stackrel{K}{\rightleftharpoons} \mathrm{D}_{\mathrm{fi}} \stackrel{\kappa_{\mathrm{u}}}{\rightleftharpoons} \mathrm{U}$

where the equilibrium constants $K$ and $K_{\mathrm{u}}$ depend on denaturant concentration, $D$ is native dimer, $D_{f i}$ is inactive, partially unfolded and fluorescently modified dimer and $U$ is monomeric, extensively unfolded subunit. The experiments presented in Figs. 1 and 2 show conclusively that between $0.9-1.2 \mathrm{M} \mathrm{GdnHCl}, \mathrm{D}_{\mathrm{fi}}$ forms under equilibrium conditions. The equilibrium constant for the formation of $D_{\mathrm{fi}}$ in the absence of $\mathrm{GdnHCl}$ $\left(K_{\mathrm{o}}\right)$ was evaluated by extrapolating a plot of $\ln K$ vs. [GdnlHCl] according to Pace [23], $K$ being determined from the inactivation transition in Fig. 1, and was found to be $2.6 \cdot 10^{-9}$. Rinas et al. [24] recently made a similar observation that dimeric blood coagulation factor XIIIa undergoes a conformational change and inactivation without dissociation to subunits as the first step in denaturation in $\mathrm{GdnHCl}$. They also observed complete dimer dissociation to subunits only in the presence of high concentrations of $\mathrm{GdnHCl}$. Liang et al. [17] also reported rapid inactivation of lobster muscle D-glyceraldehyde-3-phosphate dehydrogenase before dissociation and unfolding of the enzyme.
The conclusion that at intermediate concentrations of $\mathrm{GdnHCl}$ G6PD loses enzymatic activity without dimer dissociation to subunits is also supported by the observation that the position of the inactivation transition does not aepend on protein concentration. For a mechanism involving inactivation with dissociation:

$\mathrm{D} \stackrel{K_{\mathrm{d}}}{\rightleftharpoons} 2 \mathrm{U}$

where the equilibrium constant $K_{\mathrm{d}}$ depends on $\mathrm{GdnHCl}$ concentration, one would expect lower concentrations of G6PD to have inactivated at lower $\mathrm{GdnHCl}$ concentrations, since monomer-dimer equilibria depend on protein concentration. This was not observed over the wide range of G6PD concentrations employed $(0.5-500 \mu \mathrm{g} / \mathrm{ml})$.

The loss of active site integrity which characterizes the intermediate $D_{f i}$ results from a conformational change (partial unfolding) which apparently exposes to solvent previously buried tryptophan residues causing a decline and red-shift in the fluorescence and a disruption in secondary structure, probably $\alpha$-helix, as evidenced from the change in $C D$. This change affects a domain which contains the active site and that unfolds independently of structure which is essential for maintaining intersubunit contact [25]. Moreover, the data presented in Fig. 2 (inset) show that in this conformationally modified dimer hydrophobic domains, originally buried, become exposed leading to slow aggregation. Similar aggregation of denaturation intermediates has been previously reported for a wide variety of proteins, usually oligomeric ones $[17,19,20,22,24,26,27]$. Above about $1.4 \mathrm{M}$ GdnHCl, $D_{i \mathrm{i}}$ undergoes further unfolding as shown by the second fluorescence and $C D$ steps and the dimer dissociates to monomers $(2 \mathrm{U})$ in the range of $2.0-2.2 \mathrm{M} \mathrm{GdnHCl}$, a transition which is evident from the decline in light scattering to a value which reflects a molecular weight of approximately one half of native G6PD (Fig. 2).

The observation that the denaturation transition as followed both by enzymatic activity and by intrinsic fluorescence was not shifted to higher denaturant concentration in the presence of saturating concentrations of either glucose 6-phosphate or $\mathrm{NADP}^{+}$was unexpected, since ligand binding to the native form of a protein tends to stabilize it [28]. It is possible, but unlikely, that each of these two ligands remains bound to G6PD throughout the denaturation transition so that the preferential stabilization of the native enzyme is lost. Alternatively, if low concentrations of $\mathrm{GdnHCl}$ cause the dissociation of the ligand prior to, and independent of, G6PD denaturation, then the ligand would also lose its ability to preferentially stabilize the native enzyme. Direct studies of glucose 6-phosphate and $\mathrm{NADP}^{+}$binding to G6PD in the presence of $\mathrm{GdnHCl}$ are needed to clarify this phenomenon. 
The kinetics of G6PD denaturation with $1.4 \mathrm{M}$ $\mathrm{GdnHCl}$ shown in Fig. 3 clearly demonstrate that the fluorescence is lost in a transition which does not affect enzymatic activity, since fluorescence is lost 3-times faster than the latter and both processes are independently first-order. Thus, it appears that a partially unfolded but active species of G6PD $\left(D_{f}\right)$ also forms transiently during the approach to equilibrium. Thus the denaturation mechanism becomes:

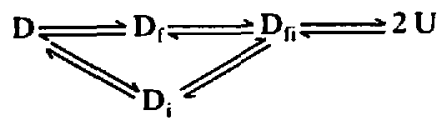

where the modifications that produce $D_{f}$ (the species with modified fluorescence) and $D_{i}$ (inactive G6PD) occur independent of each other and possibly involve different domains of the protein, so that $D$ and $D_{i}$ inactivate (to $D_{i}$ and $D_{f i}$ ) at the same rate. The data presented in Fig. 4 clearly demonstrate the strong dependence of the rate of decline in G6PD fluorescence on the concentration of denaturant. More interestingly, when $\mathrm{GdnHCl}$ is $1.7 \mathrm{M}$ or above, the reaction becomes biphasic with a fast drop in fluorescence to below the equilibrium value being followed by a slower increase. The latter was found to be first-order with a rate of about $0.33-0.37 \mathrm{~min}^{-1}$, which was largely independent of $\mathrm{GdnHCl}$ concentration. Since in the relevant $\mathrm{GdnHCl}$ concentration range, $1.7-1.9 \mathrm{M}$, the enzyme dimer does not dissociate (Fig. 2), we conclude that this second phase represents a conformational transition in the dimer, forming other partially unfolded, dimeric intermediates $\left(D_{f^{*}}\right.$ and $\left.D_{f^{*}}\right)$, which develop subsequent to the initial transition induced by denaturant (and whose rate depends on denaturant concentration). A denaturation mechanism compatible with all the above mentioned observations is:

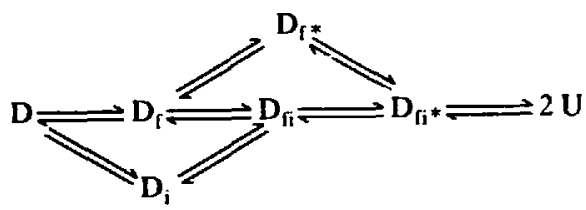

The relative concentration of dissociated subunits becomes predominant only above $2.0 \mathrm{M} \mathrm{GdnHCl}$ (see Fig. 2). The numerical value of the rate constant for the second fluorescence transition, and the observation that this rate is not sensitive to $\mathrm{GdnHCl}$ concentration are compatible with the possibility that this transition represents isomerization of Xaa-proline peptide bonds. The latter process is known to occur on the time scale of 1-7 min during the unfolding of small model peptides [29]. This second transition probably also occurs at $\mathrm{GdnHCl}$ concentrations less than $1.7 \mathrm{M}$ but is masked by the initial transition (which generates $D_{f}$ and $D_{f i}$ ), which at these concentrations becomes slower.
Fig. 5 clearly demonstrates that when $\mathrm{GdnHCl}$ in the range of $1-2 \mathrm{M}$ is diluted to a concentration that would be expected to support native G6PD, the inactive dimeric species are able to reactivate only minimally and most of the fraction of inactive protein aggregates and precipitates out of solution. The inability to reactivate develops with the time of incubation with denaturant parallel to the formation of $D_{f_{i}}$ as shown in Fig. 6. This behavior again reflects that $D_{f i}$ and $D_{f_{1}^{*}}$ are in a conformational state characterized by exposed hydrophobic stretches of the polypeptide chain. A similar effect has been observed for pig muscle lactic dehydrogenase [30]. Removal of $\mathrm{GdnHCl}$ by dilution leads to rapid, incorrect, intermolecular interactions between these hydrophobic stretches resulting in aggregation and precipitation rather than allowing the correct hydrophobic core of the native protein to reform [6]. When G6PD is denatured more extensively with higher concentrations of $\mathrm{GdnHCl}$, its ability to reactivate upon denaturant dilution improves since $D_{1 i}$ and $D_{f_{1}^{*}}$ are increasingly avoided by more complete unfolding. Similarly, it was shown that an associated $\mathrm{GdnHCl}$ denaturation intermediate of bovine growth hormone is relatively insoluble in the absence of $\mathrm{GdnHCl}[31,32]$. This intermediate precipitates rather than renatures when $\mathrm{GdnHCl}$ is removed. The possibility that covalent modifications develop in G6PD during denaturation producing enzyme forms which aggregate during renaturation is unlikely since higher denaturing concentrations of $\mathrm{GdnHCl}$ would be expected to enhance such damage and to progressively decrease reactivation rather than increase it as observed. Furthermore, the finding that precipitated G6PD is reactivatible is also evidence against the possibility that covalent damage to G6PD is responsible for aggregation.

While equilibrium studies of G6PD reactivation, as here reported, can yield a wealth of information about this process, it is clear that for a more complete resolution between potential refolding and reassociation pathways, including aggregation, complementary kinetics data are indispensible. Such studies are currently underway.

\section{Acknowledgements}

This work was supported by a Presidential Initiative Fund award to the University of Michigan from the W.K. Kellogg Foundation and by a grant from the Office of Naval Research. J.J.P. was supported by a training grant from the National Institute on Aging (T32AG00114).

\section{References}

1 Creighton, T.E. (1990) Biochem. J. 270, 1-16.

2 Jaenicke, R. (1987) Prog. Biophys. Mol. Biol. 49. 117-237. 
3 Jaenicke, R. and Rudolph, R. (1980) in Protein Folding (Jaenicke, R., ed.), pp. 525-548, Elsevier, Amsterdam.

4 Wetlaufer, D.B. and Ristow, S. (1973) Annu. Rev. Biochem, 42, 135-158.

5 Goldberg, M.E. (1985) Trends Biochem. Sci. 10, 388-391.

$6 \mathrm{Ja}$ 'nicke, R. and Rudolph, R. (1986) Methods Enzymol. 131, 218-250.

7 DeMoss, R.D., Gunsalus, I.C. and Bard, R.C. (1953) J. Bacteriol. $66,10-16$.

8 Olive, C. and Levy, H.R. (1971) J. Biol. Chem. 246, 2043-2046.

9 Kurlandsky, S.B., Hilburger, A.C., and Levy, H.R. (1988) Arch. Biochem. Biophys. 264, 93-102.

10 Haghighi, B. and Levy, H.R. (1982) Biochemistry 21, 6421-6428.

11 Adams, M.J., Levy, H.R., and Moffat, K. (1983) J. Biol. Chem. 258, 5867-5868.

12 Haghighi, B. and Levy, H.R. (1982) Biochemistry 21, 6429-6434.

13 Haghighi, B., Flynn, T.G., and Levy, H.R. (1982) Biochemistry 21, 6415-6420.

14 Bradford, M. (1976) Anal. Biochem. 72, 248-254.

15 Olive. C., Geroch, M.E., and Levy, H.R. (1971) J. Biol. Chem. 246, 2047-2057.

16 Nozaki, Y. (1972) Methods Enzymol. 26, 43-50.

17 Liang, S., Lin, Y., Zhou, J., Tsou, C., Wu, P., and Zhou. Z. (19 ill Biochim. Biophys. Acta 1038, 240-246.

18 Timasheff, S.N. and Townsend. R. (1970) in Physical Principles and Techniques of Protein Chemistry, Part B (Leach, S.J., ed.), pp. 147-208. Academic Press, New York.
19 Parr, G.R. and Hammes, G.G. (1975) Biochemistry 14, 1600-1605. 20 Jaenicke, R., Vogel, W., and Rudolph, R. (1981) Eur. J. Biochem. $114,525-531$.

21 Yao, Q-Z., Tian, M., and Tsou, C-L. (1984) Biochemistry 23, 2740-2744.

22 Herold, M. and Kirschner, K. (1990) Biochemistry 29, 1907-1913.

23 Pace, C.N. (1986) Methods Enzymol. 131, 266-280.

24 Rinas, U., Risse, B., Jaenicke, R., Abel, K.-J. and Zettlmeissl, G. (1990) Biol. Chem. Hoppe-Seyler 371, 49-56.

25 Tsou, C-L. (1986) Trends Biochem. Sci. 11, 427-429.

26 Zettlmeissl, G., Teschner, W., Rudolph, R. Jaenicke, R. and Gade, G. (1984) Eur. J. Biochem. 143, 401-407.

27 Brems, D.N. (1990) in Protein Folding: Deciphering the Second Half of the Genetic Code (Gierasch, L.M. and King, J., Eds.) pp. 129-135, American Association for the Advancement of Science. Washington.

28 Tanford, C. (1968) Adv. Prot. Chem. 23, 218-282.

29 Brandts, J.F., Halvorson, H.R., and Brennan, M. (1975) Biochemistry $14,4953-4963$.

30 Zettlmeissl, G., Rudolph, R., and Jaenicke, R. (1979) Biochemistry $18,5567-5571$.

31 Brems, D.N., Plaisted, S.M., Havel, H.A., Kaufman, E.W., Stodola, J.D., Eaton, L.C., and White, R.D. (1985) Biochemistry 24, 7662-7668.

32 Brems, D.N. (1988) Biochemistry 2i, 4541-4546. 